\title{
Investigating the Potential market of a Serious Game for Training of Alzheimer's Caregivers in a Northern Spain region
}

\author{
Jon Arambarri ${ }^{1}$, Isabel de la Torre², Miguel López-Coronado², Itziar Álvarez ${ }^{3}$ \\ 1,*VirtualWare Labs Foundation, jarambarri@virtualwaregroup.com \\ ${ }^{2}$ Department of Signal Theory and Communications. University of Valladolid, \\ isator@tel.uva.es, miglop@tel.uva.es \\ ${ }^{3}$ Home Care Lab, S. Coop., ialvarez@grupossi.es
}

\begin{abstract}
Gamification can provide new perspectives to help training people with Alzheimer and their caregivers. In this paper is shown the technical and social feasibility of launching on the market a serious game for training of Alzheimer's caregivers. A use case in the north of Spain has been selected. Before that, a state of art of serious games in the field of dementia has been done. The study showed that no serious game is available on the market focused on a widespread pathology such as Alzheimer. We have thus decided to develop and launch training products that fit Alzheimer patients and their family's needs, exploiting the learn by doing methodology, a mix of learning in everyday practices, from experience, from other people involved, and from the affected person.
\end{abstract}

Keywords: Alzheimer, Caregivers, Gamification, Social Impact

\section{Introduction}

The aging population and their care have become major socio-economic challenges of the XXI century. In the next future, Europe will have less working people. This is a highly risk challenge for the European economies if they want to continue growing and remain competitive in a global world. In 2010, Spain had more people over 65 than children aged 0 to 14 years. People over 65 represented $16.9 \%$ of total population of the country [1]. According to the perspectives of Spanish National Institute of Statistics, this figure will increase to 14.7 million in $2050,33.5 \%$ of the projected population by then. Regarding older people with disabilities in Spain, at the beginning of this decade there were almost two and a half million. This figure is expected to increase $76.8 \%$ in 2020 [2]. Therefore, in the coming years, significant and progressive populations increase for dependent both due to the growth of the population over 65 , and by the demographic phenomenon known as "aging - aging" is expected. Changes in the population pyramid, will locate Spain among the more aged countries of the European Union with a life expectancy that would reach 87.9 years for women and 81.4 years for men in a four decades period [3-6].

Several studies show a clear reciprocity between age and disability and dependency situations [7-8]. To this situation dependency due to illness and other causes of disability or limitation must be added. These other types of dependency have also increased in recent years by changes in survival rates of certain chronic diseases and congenital disorders and the consequences of the indices of road and workplace accidents.

Thus, Spanish health system, designed for the patient from the 60's or 80's, fails so clearly on giving an accurate attention to new coming dependency needs. Even though, it would be relatively simple to fill aging people needs by designing a patient centered approach.

The Spanish health and social system have been characterized so far by working in a poorly coordinated way between themselves. However, in many cases the dependence is underlying a health problem (Alzheimer, arthritis, stroke, etc.). The attention paid for dependents in the National health care system has effects on problems served by the system social, and vice versa [9-11].

In this context, gamification could play an important role as a key factor to enhance training activities of people with dementia (mainly Alzheimer) and their caregivers. Serious games can be a wonderful addition the life in a home environment. These games stimulate activities and habits and are appropriate at different stages of the disease. Moreover, they can maximise early cognitive abilities 
to enable to patient to record her/his own memory. The main objective of this paper is to show a new application domain of serious games and the social feasibility of launching a new application to the market for this purpose. The out coming Serious Game is primarily aimed at private users and associations of dementia (Alzheimer's), patients-care businesses and health sector agencies supporting such pathology in Basque Country region (Spain).

\section{Methodology}

In order to study the release of the game, a research about the needs of the end users, the caregivers, was conducted, through the organization Grupo Servicios Sociales Integrados, S. Coop., which globally responds to the social needs of people in situations of dependence and social vulnerability, and their families, in Euskadi.

This research has been carried out in different stages. Firstly, an analysis of documentation was made. The characteristics and general symptoms of the Alzheimer disease, as well as, the situations that are considered difficult to manage for family caregivers were identified, and a theoretical framework was developed. This framework was the baseline the further analysis.

In a second phase, individual semi-structured interviews with family caregivers were conducted. With these interviews subjective information was collected regarding the symptoms of the person with Alzheimer, and the answers of the caregivers. To do this, an "ad hoc" questionnaire was developed to collect information about socio-demographic data of the family caregiver and the dependent person, the managing of difficult situations (these are included through examples, avoiding use of jargon), the responses of the family to these situations, and observations. The information of the interviews was moved to a database, and the data was exploited.

In a third phase, individual semi-structured interviews and focus groups with professionals (professionals that work with people with the disease and with family caregivers, and carers of the home care service) were conducted. The objective of this phase was to get recommendations of professionals for the managing of difficult situations that may appear in the care of people with Alzheimer disease and then contrast the responses of the family caregivers.

\section{State of Art of Serious Games in the field of dementia}

According to Gartner, Inc. for the year 2015, the 50 companies of the world should embrace the concept of gamification, using game techniques in tasks not initially associated with the game [1219]. There are many types of serious games depending on their goal. Examples of serious game are, for example Steve 20 system, which has got in a virtual environment to interact [20]. In this way, the virtual tutor performed shows that facilitated the learning of students. Other examples are SQLTutor [21] and Cosmo [22], in the field of computer science teaching.

Nintendo introduced its Wii console in a new mode of interaction, in which the players use gestures and hand movements. Finally, Microsoft Kinect uses a camera with information depth to make the position and movements of the Player body control the characters. These are examples of perceptual, necessary technologies to allow computers to interact with people in a similar way as the people make it. Developers must decide if they adapt existing interaction techniques or design new techniques that exploit the characteristics of new devices. It is necessary a research effort in the field of new interaction techniques, including Virtual Reality and Augmented Reality, multimodal interfaces, new devices of sound, etc. that will enrich the experience in serious games.

The development of new formats in the video game industry has been directed towards the consoles of movement, which are characterized by the fact that the user has to move with some or all parts of your body with the purpose of that console capture movement and realized within the game that is being displayed on a TV screen.

The market features products that they are hardly in full development of their potential and only have a few years on the market. They have a number of limitations that make it necessary to improve these systems. The main limitation is characterized by limit the gameplay in game space and in the number of players that can participate simultaneously. This is because the gestures that user should make in their homes to make impossible virtually for more than two people to play to the most innovative systems such as Kinect.

Serious games focused on pathologies like dementias do not exist in the market [23-27]. Some of the main products made in the field of serious games in relation to neurodegenerative diseases are: Dakim BrainFitness (www.dakim.com), CogniFit (www.cognifit.com), R.O.G.E.R (Realistic 
Observation in Game and Experiences in Rehabilitation, http://blog.fishingcactus.com), SuperBetter (www.superbetter.com), MINDs (http://minwii.org/), Congestive Heart Failure (http://www.kognito.com), VirtualRehab (http://virtualwaregroup.com), Smartbrain Games y Smartbrain Pro (http://www.smartbrain.net), etc. Table 1 shows a summary of the main products made in the field of serious games in relation to neurodegenerative diseases.

Table 1.Approach to serious games in the field neurodegenerative diseases

\begin{tabular}{|c|c|c|}
\hline Product Name & Users & Objective \\
\hline Dakim BrainFitness & $\begin{array}{c}\begin{array}{l}\text { People over } 60 \text { years old with and } \\
\text { without cognitive impairment } \\
\text { Professionals }\end{array} \\
\end{array}$ & $\begin{array}{c}\begin{array}{l}\text { Stimulation of cognitive functions } \\
\text { to prevent cognitive impairment or } \\
\text { to retard progress }\end{array} \\
\end{array}$ \\
\hline CogniFit & $\begin{array}{l}\text { A wide range of People age with and } \\
\text { without cognitive impairment }\end{array}$ & Cognitive funtions stimulaion \\
\hline $\begin{array}{c}\text { R.O.G.E.R (Realistic } \\
\text { Observation in Game and } \\
\text { Experiences in Rehabilitation) } \\
\end{array}$ & Patients over 17 years old & Rehabilitation \\
\hline SuperBetter & General population and ill people & Psychological intervention \\
\hline MINDs & People with Alzheimer's disease & Music Therapy \\
\hline Congestive Heart Failure & Patients with heart failure and family & Training \\
\hline VirtualRehab & $\begin{array}{l}\text { People with neurodegenerative diseases } \\
\text { or acquired brain injury }\end{array}$ & Physical rehabilitation \\
\hline $\begin{array}{c}\text { Smartbrain Games y Smartbrain } \\
\text { Pro }\end{array}$ & $\begin{array}{l}\text { Older people in the first case and people } \\
\text { with cognitive impairment in the second }\end{array}$ & Cognitive Stimulation \\
\hline
\end{tabular}

\section{Launching a game by Alzheimer's caregivers in a region in north of Spain}

After a previous work of researching serious games focused on Alzheimer and other dementias, the absence of disease-focused games such as dementia provide an opportunity to develop this kind of games. Many of them for the training of family members and caregivers. For this main reason, Virtualware Group decided to develop a serious game to help to Alzheimer's patients and their caregivers.

The main market for the product to be developed will focus on the Basque and Spanish context, of: professionals (companies and associations), families of people with Alzheimer type dementia and public health-related entities. This focus of the market is based on the information specified in paragraph of state of the art, which referred, first, to the increase of people in situations of dependency where one of the conditions that caused it were the Dementias (especially Alzheimer) and on the other hand, the main actors involved in supporting them; families, professionals and the public health and social systems. This decision on the target market is supported by the huge number of people who care in situations of dependency.

The main goal is to begin commercial broadcast and distribution by institutions of the Basque Country, and progressively move forward to the rest of the state. Regarding the current profile of caregivers of patients with Alzheimer type dementia, although the majority is older people, especially in the family, the question of technology is a barrier that is starting to win, and forecast future, the majority of older people will dominate the use of technology. In Table 2, a forecast of market research is shown.

Table 2. Forecast potential market

\begin{tabular}{c|c|c}
\hline Type of users & Statistics Data & Market \\
\hline Private & $\begin{array}{c}200,000 \text { and 500,000 in Spain about } \\
\text { people affected by Dementia (Alzheimer } \\
\text { mainly) }\end{array}$ & $\begin{array}{c}\text { Campaigns product would be an } \\
\text { evolution of 1 to 5\% (2,000 to } \\
10,000), \text { which would be a } \\
\text { resounding success of the product }\end{array}$ \\
\hline Public & $\begin{array}{c}\text { More than 300 entities related to } \\
\text { assistance to people with dementia }\end{array}$ & $\begin{array}{c}\text { About 10 to 30 entities (starting } \\
\text { with the Basque Country and } \\
\text { neighbouring communities) }\end{array}$ \\
\hline
\end{tabular}

\section{Discussion and Conclusion}

Dementia is a highly prevalent disease worldwide, especially in older populations, as its prevalence and incidence increases exponentially with age. The leading cause of dementia is Alzheimer's 
disease, followed by through mixed pathology and vascular. If future forecasts are correct, a true global epidemic is expected.

At present, family caregivers or not formally professional caregivers represents $85 \%$ of the group in a situation of dependency, where the typical profile is: female, between 45 and 69 years old and married. The progressive incorporation of nearly three million women in the last decade has introduced new labor market factors that make it imperative to reform the traditional care system to ensure adequate capacity to provide care to those in need. Serious Games could be useful in this regard, providing methods of learning for caregivers based on learning from day to day, learn from others, learn from experience and learn from the affected individual.

The future of care dependency and chronicity in the area of the home is unavoidably linked to the humanization of the disease, customizing services, skilled attendance, the use of new technologies and the development of care household as a whole, and the establishment of partnerships with all the resources of the various levels of care. Some main benefits that we expect from gamification in socio-centered health-care involve: improving care participation and responsibility of the patient and their families, improving the quality of life, increasing profitability of hospital resources, increasing efficiency and effectiveness through assistance more humanized.Application of gamification to support Alzheimer patients may open significant market perspectives and stimulate research challenges. In this paper we have analyzed the technical and social feasibility of launching a new serious game in the field of Alzheimer's disease targeted at families and careers. Despite the focus was in a Spanish region, we believe that results could also be generalized to the whole population European or even global.

\section{Acknowledgements}

This project has been partially supported by the Departamento de Industria, Comercio y Turismo del Gobierno Vasco (Spain) under the project GAITEK - IG-2013/01314.

\section{References}

[1] Briggs, A., Sculpher, M., “An introduction to Markov modelling for economic evaluation”. Pharmacoeconomics, 13:397-409, 1998. http://dx.doi.org/10.2165/00019053-19981304000003

[2] García-Armesto, S., Abadía-Taira, M.B., Durán, A., et al., "Health system review. Health Systems in Transition, European Observatory on Health Systems and Policies", 2(4), 2010.

[3] Maierhofer, S., Almazán-Isla, J., Alcalde-Cabero, E., de Pedro-Cuesta, J., "Prevalence and features of ICF-disability in Spain as captured by the 2008 National Disability Survey". BMC Public Health,11:897, 2011. http://dx.doi.org/10.1186/1471-2458-11-897

[4] PriceWaterHouseCoopers. "Situation of Long-Term Care Services in Spain". http://www.asociacion-aeste.es/comun/documentacion/situacion_at_re esp_2010.pdf. Accessed 16 June 2014.

[5] Institute for Older Persons and Social Services. Elderly in Spain. Community statistical Data Datos. Report 2008, Book 1, Madrid, 2009.

[6] Abellán, A., Sancho, M., Barrio, E., Esparza, C., "Current demographic trends. White Paper on Active Ageing", Madrid:33-79, 2011.

[7] Rodriguez, G., Rodríguez. P., Castejón, P., Morán, E., “Older people who came. Autonomy, Solidarity and Social Participation". Pilares Foundation for personal autonomy. http://www.fundacionpilares.org/laspersonasmayoresquevienen.php. Accessed 16 June 2014.

[8] Rodriguez, L., "Home care for older people: not everything goes". Revista española de salud pública 2003;77(5):523-526.

[9] Rodriguez, P., "Integral attention and focused on people". Pilares Foundation for personal autonomy. http://www.fundacionpilares.org/docs/AICPweb.pdf. Accessed 16 June 2014.

[10] Institute for Older Persons and Social Services. White Paper Caring for people in situations of dependency in Spain, Madrid, 2005.

[11] Institute for Older Persons and Social Services. White Paper on care coordination in Spain, Madrid, 2011.

[12] Martínez, T. Gerontological care focused on people. Guide to professional intervention in schools and care services for older people in situations of fragility or dependency. VitoriaGasteiz, Basque Government, 29-33, 2011. 
[13] Ayres, A., Can online innovations enhance social care? Exploring the challenges of using digital technology to develop new models of support for older people. http://www.nominettrust.org.uk/sites/default/files/Enhancing\%20social\%20care_PP_0113.pdf. Accessed 17 June 2014.

[14] Barbabella, F., "Assessing the impact of ICT-based solutions for carers in Europe: preliminary findings from the CARICT project", Zentrum für Soziale Innovation Discussion Paper, number 14, 2012. https://www.zsi.at/attach/DP14_Barbabella_et_al.pdf. Accessed 17 June 2014.

[15] Documentation Center and studies SIIS Dokumentazio ETA Ikerketa ZentroA. I Resport about the situation of social services in Euskadi. Vitoria-Gasteiz: Basque Government, 2011.

[16] Basque Government. Strategic Plan for social services in the Basque Country. 2011-2014. Analysis of the initial situation, preliminary diagnosis and proposed basic strategic lines. Vitoria-Gasteiz: Basque Government, 2009.

[17] Basque Government. One hundred proposals to advance the welfare and proper treatment of aging people. Basis for Action Plan. Vitoria-Gasteiz: Basque Government, 2011.

[18] Monteagudo, J.L., "Capabilities and opportunities for innovation in ICT for Alzheimer", Madrid: Telemedicine Research Unit - Instituto de Salud Carlos III.

[19] Rossi, A. Technological solutions potentially influencing the future of long-term care. ENEPRI Research Report $\quad \mathrm{n}^{\circ} \quad 114 . \quad$ http://www.ancienlongtermcare.eu/sites/default/files/RR\%20No\%20114\%20_ANCIEN\%20WP4_\%20Technolo gical\%20Solutions.pdf. Accessed 17 June 2014.

[20]Elliott, C., Rickel, J., Lester, L., "Lifelike Pedagogical Agents and Affective Computing An Exporatory Synthesis". Institute for Applied Artificial Intelligence, School of Computer Science, Telecommunications, and Information Systems, DePaul University. Chicago 2000. http://dx.doi.org/10.1007/3-540-48317-9_8

[21] Suraweera, P., An Animated Pedagogical Agent for SQL-Tutor 1999.

[22] Lester, J., Voerman, J.L., et al., "Cosmo: A Life-like Animated Pedagogical Agent with Deictic Believability". In Proceedings of the IJCAI97 Workshop on Animated Interface Agents.

[23] Bouchard, B., Imbeault, F., Bouzouane, A., Menelas, B.A.J., "Developing Serious Games Specifically Adapted to People Suffering from Alzheimer. Serious Games Development and Applications". Lecture Notes in Computer Science, 7528, 243-254, 2012. http://dx.doi.org/10.1007/978-3-642-33687-4_21

[24] McCallum, S., Costas, B., "Dementia Games: A Literature Review of Dementia-Related Serious Games. Serious Games Development and Applications. "Lecture Notes in Computer Science, 8101, 15-27, 2013. http://dx.doi.org/10.1007/978-3-642-40790-1_2

[25] Robert, P.H., et al., "Recommendations for the use of Serious Games in people with Alzheimer's Disease, related disorders and frailty". Front Aging Neurosci, 6:54, 2014. http://dx.doi.org/10.3389/fnagi.2014.00054

[26] Lu, AS., "Serious Games for Healthcare: Applications and Implications". Games for Health Journal, 2(5):313-314, 2013. http://dx.doi.org/10.1089/g4h.2013.0062

[27] Kayama, H., Okamoto, K., Nishiguchi, S., et al., "Effect of a Kinect-Based Exercise Game on Improving Executive Cognitive Performance in Community-Dwelling Elderly: Case Control Study". Journal of Medical Internet Research, 16(2):e6, 2014. http://dx.doi.org/10.2196/jmir.3108 